\title{
Successful treatment of severe pneumonia, pyopneumothorax with severe acute respiratory distress syndrome, and septic shock: a case report
}

\author{
Xi Wang, Jian Lan", Ruijie Zhang and Xiaoqing Luo
}

\begin{abstract}
Background: This article reports a patient who survived severe pneumonia, pyopneumothorax with acute respiratory distress syndrome (ARDS), and septic shock, which is very difficult to treat.

Case presentation: Antibiotics, continuous renal replacement therapy (CRRT), bronchial lavage and other treatments were used to treat a patient with pneumonia, pyopneumothorax, severe ARDS and septic shock. After comprehensive treatment, the patient was successfully treated and survived for a long time.

Conclusions: There is a low successful clinical treatment rate for patients with pneumonia, pyopneumothorax with severe ARDS and septic shock. The successful treatment of this patient benefited from early and effective empirical therapy, targeted drug selection in the later stage, adequate closed thoracic drainage, repeated bronchial lavage, early CRRT, an appropriate respiratory support mode and parameter setting, immunotherapy and nutritional support therapy. This paper proposes a reference diagnosis and treatment solution for similar cases.
\end{abstract}

Keywords: Severe pneumonia, Acute respiratory distress syndrome (ARDS), Septic shock, Continuous renal replacement therapy (CRRT), Mechanical ventilation

\section{Background}

According to recommendations from the Infectious Diseases Society of America/American Thoracic Society (IDSA/ATS), the main diagnostic criterion for severe pneumonia should be the need for invasive mechanical ventilation or the presence of vasoconstrictor-requiring septic shock. Severe pneumonia can induce ARDS. Severe ARDS can be diagnosed when the oxygenation index (OI) is lower than $100 \mathrm{mmHg}$ (positive end expiratory pressure (PEEP) $\geq 5 \mathrm{cmH}_{2} \mathrm{O}$ ), leading to $46.1 \%$ hospital mortality [1]. For ARDS treated with mechanical ventilation, the incidence of pneumothorax is $6.5 \%$, and

*Correspondence: 201647964@qq.com

The Second Affiliated Hospital of Chongqing Medical University,

Chongqing, China the mortality rate in that case is $51.4 \%$ [2]. Severe pneumonia may lead to sepsis and life-threatening organ dysfunction. ARDS associated with sepsis has a higher mortality rate than that with nonsepsis [3].

At present, there are no clinical guidelines for the treatment of severe pneumonia, pyopneumothorax with severe ARDS and septic shock. Studies have shown that early initiation of CRRT is associated with favorable clinical outcomes in ARDS patients [4]. We will share a successful case here. The present patient was critically ill, with a rapid progression of his condition. He was discharged from the hospital after receiving comprehensive treatment, including early CRRT, and has survived to this day.

c) The Author(s) 2020. This article is licensed under a Creative Commons Attribution 4.0 International License, which permits use, sharing, adaptation, distribution and reproduction in any medium or format, as long as you give appropriate credit to the original author(s) and the source, provide a link to the Creative Commons licence, and indicate if changes were made. The images or other third party material in this article are included in the article's Creative Commons licence, unless indicated otherwise in a credit line to the material. If material is not included in the article's Creative Commons licence and your intended use is not permitted by statutory regulation or exceeds the permitted use, you will need to obtain permission directly from the copyright holder. To view a copy of this licence, visit http://creativeco mmons.org/licenses/by/4.0/. The Creative Commons Public Domain Dedication waiver (http://creativecommons.org/publicdomain/ zero/1.0/) applies to the data made available in this article, unless otherwise stated in a credit line to the data. 


\section{Case presentation}

A 65-year-old man was admitted to the respiratory intensive care unit (RICU) on December 15, 2018, after experiencing symptoms of fever, cough, and left chest pain for 10 days and dyspnea for 1 day. He had had hypertension, diabetes mellitus and diabetic nephropathy for many years and had controlled these conditions by taking medication. On admission, the patient showed high scores of 21, 4, and 6, respectively, on the Acute Physiology and Chronic Health Evaluation II (APACHE II), SOFA, and Geneva scales. His bedside chest film showed serious left pleural effusions with right lung inflammation (Fig. 1a), and rising inflammatory markers (white blood cells (WBC) $27.55 * 10^{9} / \mathrm{L}$, procalcitonin
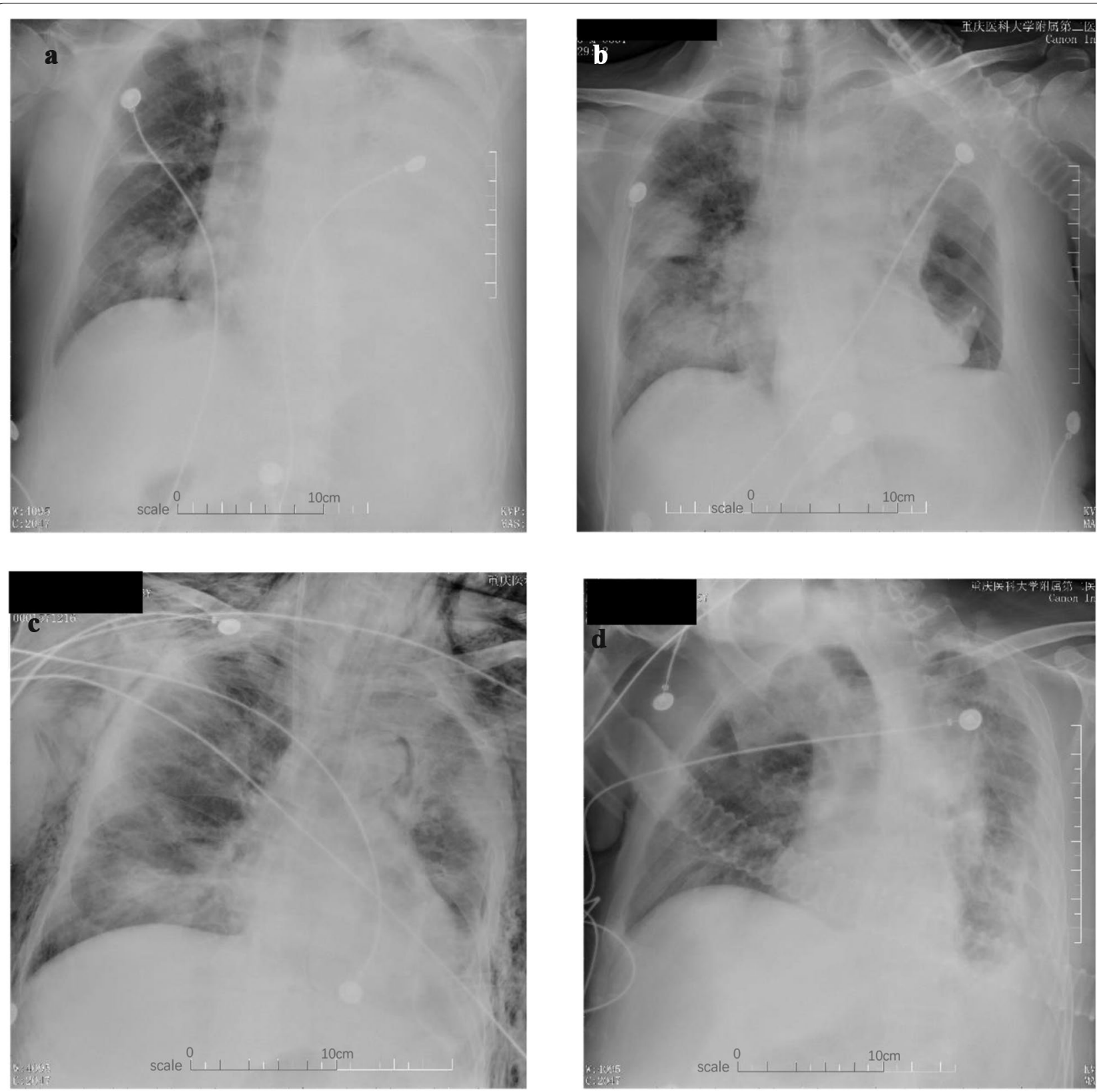

Fig. 1 Series of bedside chest films: a A large quantity of left pleural effusions with inflammation of the right lung; $\mathbf{b}$ The left pleural effusion was partly absorbed while the encapsulated gas was added, and the shadow of the right lower lung mass became larger and thicker; $\mathbf{c}$ Pneumatosis occurred in the mediastinum, and an extensive accumulation of gas was found in both sides of the neck and under the skin of the chest wall; $\mathbf{d}$ The inflammation of both lungs was reduced, and the subcutaneous gas was basically absorbed 
(PCT) $2.8900 \mathrm{ng} / \mathrm{ml}$ and C-reactive protein (CRP) > $200 \mathrm{mg} / \mathrm{L}$ ) with some other poor laboratory results (D dimer $0.5 \mathrm{mg} / \mathrm{l}$, lactic acid $10.40 \mathrm{~mol} / \mathrm{L}$, albumin $23.4 \mathrm{~g} / \mathrm{L}$, creatinine $171.7 \mu \mathrm{mol} / \mathrm{L}, \mathrm{B}$-type natriuretic peptide precursor $1437.00 \mathrm{pg} / \mathrm{mL}$ ). The patient was treated with carbapenems and glycopeptides (Fig. 2), the antibacterial spectrum of which covered Gram-positive bacteria, Gram-negative bacteria, Pseudomonas and anaerobes. At the same time, the patient was also treated with noninvasive ventilation (ST mode, $\mathrm{FiO}_{2}$ 90\%, F 18 BPM, IPAP 13 $\mathrm{cmH}_{2} \mathrm{O}$, EPAP $5 \mathrm{cmH}_{2} \mathrm{O}$ ), cardiotonic and sodium bicarbonate. A few hours later, the patient developed irritability, cool and moist limbs and shock. A $780 \mathrm{~mL}$ purulent liquid-gas mixture was extracted from his left chest cavity, and a thoracic drainage tube was placed into the left chest for continuous drainage. Examination of the pleural effusion showed that the total number of cells was $681,889 * 10^{6} / \mathrm{L}$, and the number of nucleated cells was $245,589 * 10^{6} / \mathrm{L}$. After these measures, the patient's dyspnea was slightly relieved.

This patient worsened from his second day of admission. He began to exhibit hypotension with respiratory distress. His OI dropped to $67 \mathrm{mmHg}$. The laboratory tests yielded worse indicators-WBC $38.63 * 10^{9} / \mathrm{L}, \mathrm{PCT}$ $19.0700 \mathrm{ng} / \mathrm{m}, \mathrm{CRP}>200 \mathrm{mg} / \mathrm{L}$, BNP $4711.00 \mathrm{pg} / \mathrm{m}$ and an estimated glomerular filtration rate (eGFR) decreased to $26 \mathrm{~mL} / \mathrm{min}$. The bedside chest film showed encapsulated pneumothorax on the left chest cavity (Fig. 1b). Endotracheal intubation and invasive mechanical ventilation were implemented (P-A/C mode, $\mathrm{FiO} 2$ 100\%, F 18/min, Pi $16 \mathrm{cmH}_{2} \mathrm{O}$, PEEP 4 $\mathrm{cmH}_{2} \mathrm{O}$ ). At the same time, a sedative, an analgesic and a muscle relaxant were employed. Norepinephrine, low molecular weight heparin, enteral nutrition and parenteral nutrition support were also used. Bronchoalveolar lavage was performed to identify extensive erosion and edema of the bronchial mucosa and serious obstruction of the airway by copious purulent secretions. Daily bronchoalveolar lavage was carried out for the next 11 days to extubation.

Bedside CRRT was performed for $8-12 \mathrm{~h}$ a day for 3 consecutive days from the third day of admission, and the ultrafiltration volume was $150 \mathrm{~mL}, 100 \mathrm{~mL}$ and $1116 \mathrm{~mL}$, respectively. After CRRT, the patient maintained stable vital signs without using norepinephrine and muscle relaxants. From the 5th day of admission, gamma globulin was given at $20 \mathrm{~g}$ a day for 3 consecutive days, after which the OI of the patient increased gradually (Fig. 3). During the treatment, the sputum culture suggested yeast-like fungal growth, while multiple blood cultures did not indicate any positive results. Stenotrophomonas maltophilia, whose sensitivity test suggested that it was sensitive to minocycline, was found in the left pleural pus. Aspergillus was observed in the sputum of the endotracheal tube. Aspergillus fumigatus was present in the bronchoalveolar lavage fluid. Therefore, the

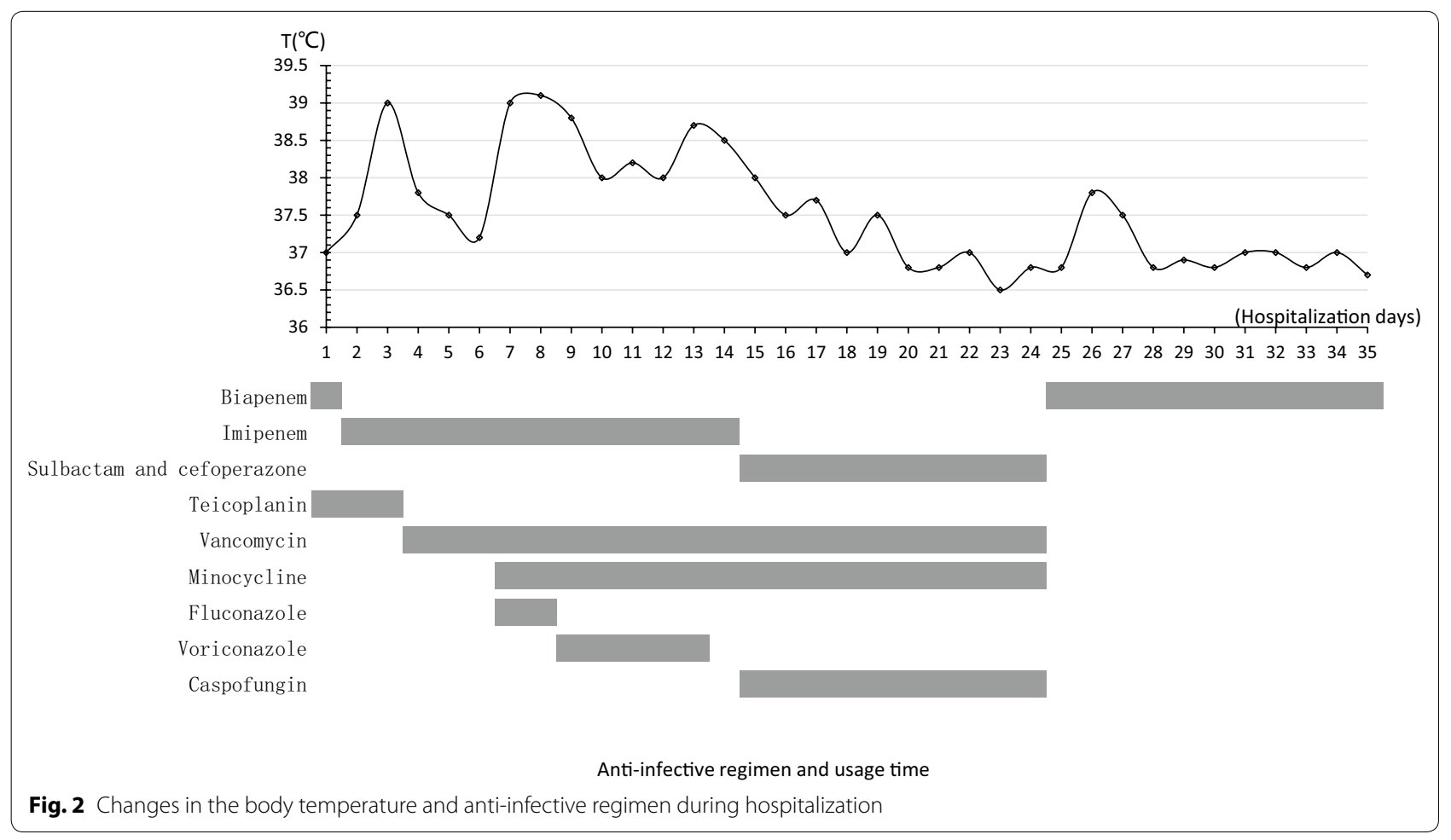




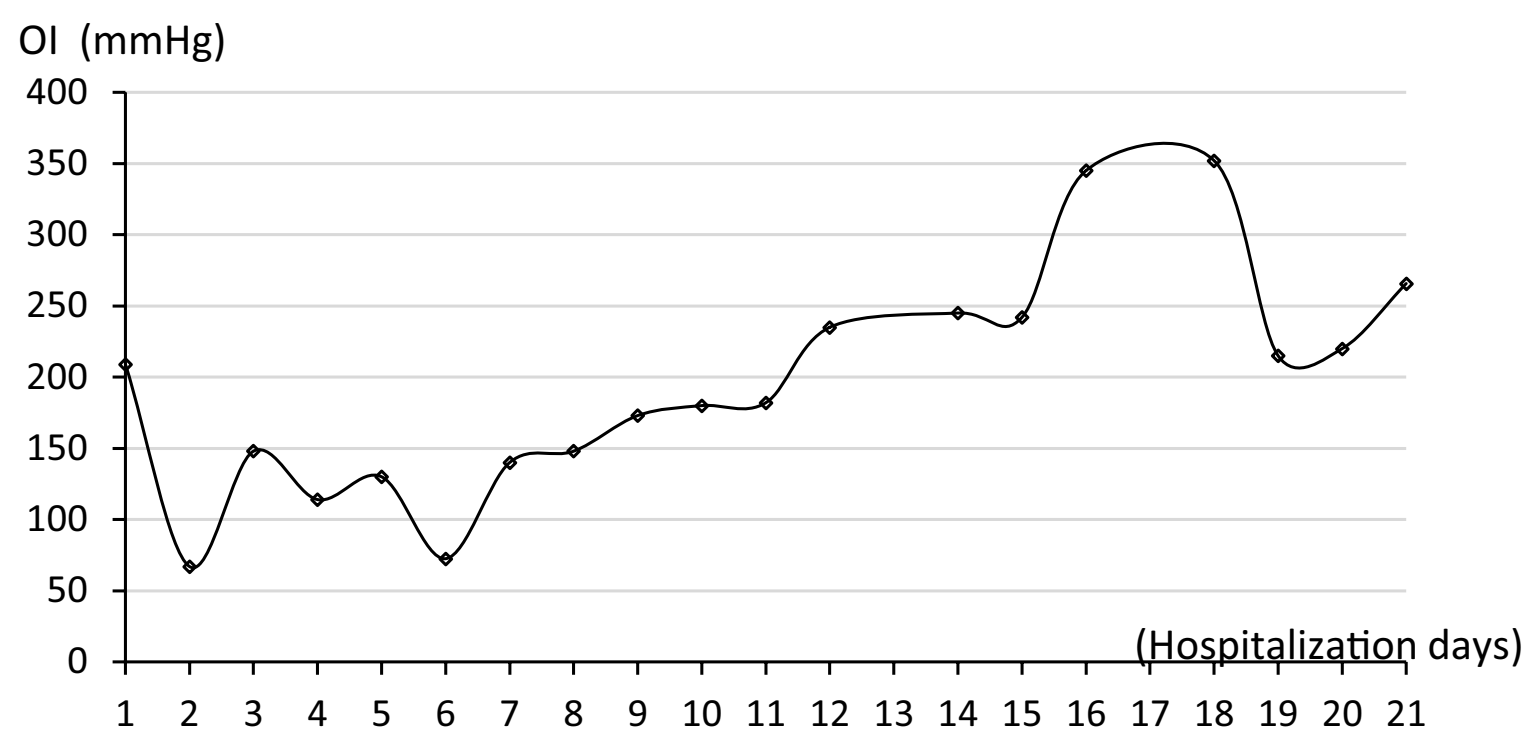

Measured value

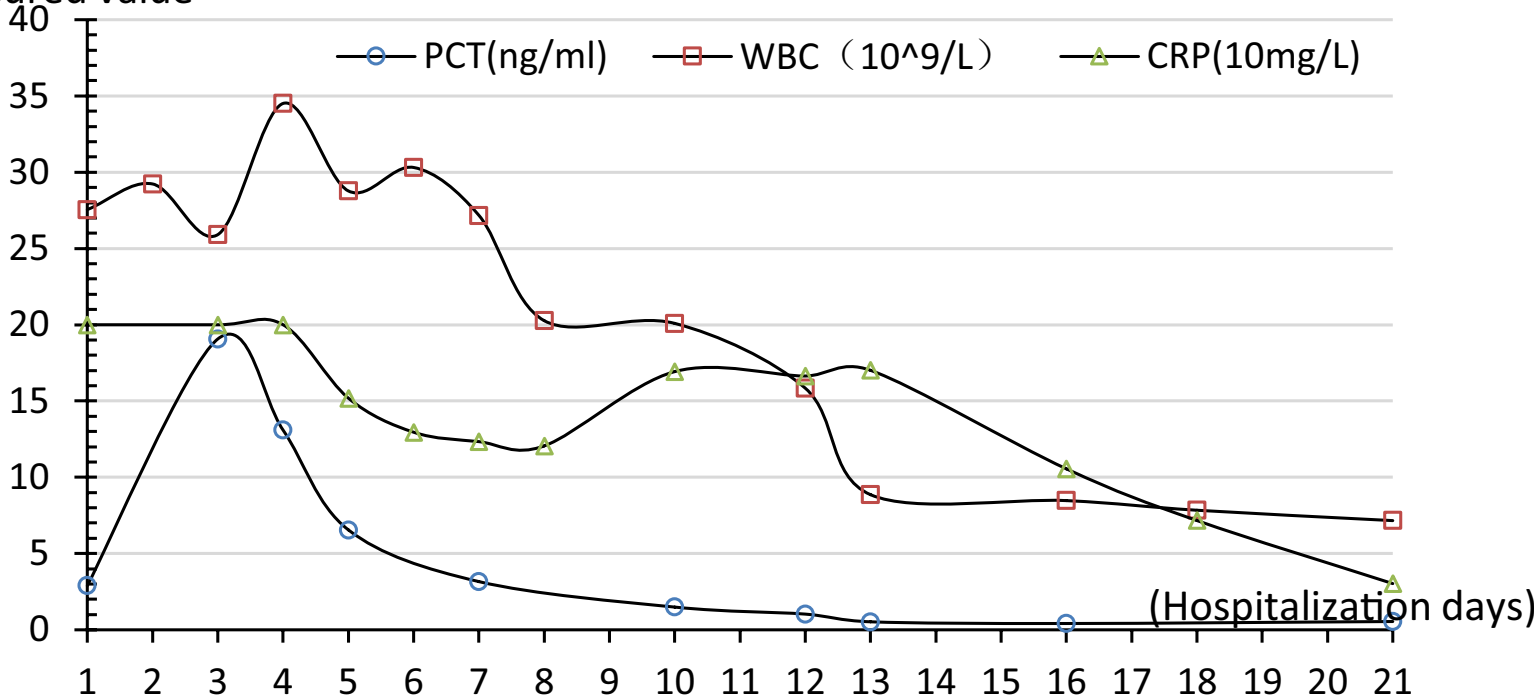

Fig. 3 Changes in the oxygenation index and inflammatory factors

treatment was supplemented with antifungal agents and minocycline.

On the 10th day, this patient developed subcutaneous emphysema with dyspnea (Fig. 1c). Considering that compression and obstruction of the drainage tube could inhibit improvement of this syndrome, the closed thoracic drainage tube was replaced. On the 12th day, the inflammatory markers continued to decrease, and the eGFR increased to $53.6 \mathrm{~mL} / \mathrm{min}$. Spontaneous breathing experiments (SBT) were performed for $2 \mathrm{~h}$, and the rapid shallow breathing index (RSBI) was 80 . Then, the endotracheal tube was removed, and the patient was switched to noninvasive mechanical ventilation. The thoracic drainage tube was removed on the 14th day, and the anti-infective regimens at that time were sulbactam, cefoperazone, vancomycin, minocycline and caspofungin. On the 17th day, the patient's bedside chest film showed reduced inflammation and basically absorbed subcutaneous gas (Fig. 1d). Nasal catheters replaced noninvasive mechanical ventilation, and biapenem was used alone to resist infection on the 21st day. The patient discharged himself from the hospital after 35 days of admission and was satisfied with the treatment method and effect. He was followed-up at the outpatient clinic of the same hospital. He is presently leading a normal life, with his eGFR remaining at $60 \mathrm{~mL} / \mathrm{min}$ (as of October 2020). 


\section{Discussion and conclusions}

The patient in the reported case had obvious respiratory distress and symptoms of infected, toxic blood. Imaging and pleural aspiration supported the diagnosis of severe pneumonia and pyopneumothorax. The patient reached the diagnostic criteria of severe ARDS and septic shock. Based on experience in severe pneumonia treatment, we have applied a wide range of anti-infection schemes and strengthened the antianaerobic therapy. In the followup treatment, we adjusted the antibiotics according to the positive bacteriological results and the drug sensitivity test. Effective antibacterial treatment was the key to improving the primary etiology and resolving the disease. The continuous drainage of pleural pus and repeated bronchoalveolar lavage also played an important role in the rapid and effective control of the infection. It has been reported that bronchoalveolar lavage is an effective treatment for mechanically ventilated patients with nosocomial pneumonia [5]. By observing multiple inflammatory indicators (Fig. 3) as monitored, the infection control measures were effective and appropriate.

Since the patient had diabetic nephropathy, we performed CRRT when his renal function began to decline, but creatinine levels did not significantly increase to protect his organs or improve the OI. It has been reported that during acute renal injury (AKI) in critically ill and elderly patients, early application of CRRT results in a better prognosis, and an eGFR lower than $30 \mathrm{~mL} /$ $\mathrm{min} / 1.73 \mathrm{~m}^{2}$ is a strong risk factor for reducing long-term survival $[6,7]$. This patient's eGFR was reduced to $26 \mathrm{~mL} /$ min during treatment. He can survive for a long time, and his eGFR, which has been maintained at $60 \mathrm{~mL} / \mathrm{min}$ during the follow-up after his discharge indicates the importance of early implementation of CRRT.

Pneumothorax is a serious complication of mechanical ventilation for patients with ARDS. The risk of pneumothorax developing into tension pneumothorax is high, and therefore, rapid drainage is needed [8]. When the patient in this case study was admitted, his chest film did not show hydropneumothorax; noninvasive ventilation was thought to have caused barotrauma, which was also one of the reasons for the patient's rapidly deteriorating condition after admission. Timely and adequate closed thoracic drainage relieved the high intrathoracic pressure and created conditions for endotracheal intubation and invasive mechanical ventilation. During the treatment, a large amount of subcutaneous and mediastinal gas accumulation was aspirated from the blocked drainage tube. This also shows the importance of adequate thoracic drainage for patients with pneumothorax during mechanical ventilation. The choice of the mechanical ventilation mode and parameters is an important factor affecting the incidence of barotrauma. There is a particularly high risk when the end-inspiratory platform pressure is above $35 \mathrm{cmH}_{2} \mathrm{O}$ [9]. Since mechanical ventilation is not conducive to healing pleural lacerations, the ventilator parameters should be set to a principle of a low PEEP and a low tidal volume with the prerequisite of an ensured OI.

Sepsis can cause a series of inflammatory cascade reactions, leading to immune disorders. The timing of targeted, personalized, and precise medical approaches to sepsis and whether sepsis or septic shock should be treated with empirical antibiotics are among the most important clinical priorities put forward by the sepsis Survival Research Committee [10]. In this case, early combined intervention including empirical antibiotic treatment is very important. CRRT, lavage and closed thoracic drainage stabilize the internal environment and earn valuable treatment time, which are significant for critically ill patients. It has been suggested in the literature that early, high-dose and long-term administration of intravenous immunoglobulin (IVIg) may improve the prognosis of patients [11]. The immunotherapy and nutritional support therapy we adopted also had a positive impact on the patient's prognosis.

In conclusion, the present patient's condition was extremely critical when admitted, and the treatment was very difficult. He was cured and survived as a result of active comprehensive treatment and intervention. As each critical patient has his or her own features, this paper proposes a reference diagnosis and treatment solution for similar cases rather than a fixed scheme.

\section{Abbreviations \\ ARDS: Acute respiratory distress syndrome; CRRT: Continuous renal replace- ment therapy; IDSA/ATS: Infectious Diseases Society of America/American Thoracic Society; Ol: Oxygenation index; PEEP: Positive end expiratory pres- sure; RICU: Respiratory intensive care unit; APACHEII: Acute Physiology and Chronic Health Evaluation II; WBC: White blood cells; PCT: Procalcitonin; CRP: C-reactive protein; BNP: Type B natriuretic peptide; eGFR: Estimated glomerular filtration rate; SBT: Spontaneous breathing experiments; RSBI: Rapid shallow breathing index; AKI: Acute renal injury; IVlg: Intravenous immunoglobulin.}

\section{Acknowledgements}

Not applicable.

\section{Authors' contributions}

All authors made substantial contributions to the conception and design, acquisition of data, analysis and interpretation of data. XW wrote the manuscript; JL contributed significantly to the manuscript preparation; RZ took part in constructive discussions; $X \mathrm{~L}$ contributed to the conception of the study. All authors read and approved the final manuscript.

\section{Funding}

None.

Availability of data and materials

The datasets used and/or analyzed during the current study are available from the corresponding author on reasonable request. 


\section{Ethics approval and consent to participate}

This study was approved by the Ethics Committee of The Second Affiliated Hospital of Chongqing Medical University.

\section{Consent for publication}

Written informed consent was obtained from the patient for publication of this case report and accompanying images. A copy of the written consent is available for review by the Editors-in-Chief of this journal.

\section{Competing interests}

Not applicable.

Received: 2 September 2020 Accepted: 29 October 2020

Published online: 11 November 2020

\section{References}

1. Bellani G. Epidemiology, patterns of care, and mortality for patients with acute respiratory distress syndrome in intensive care units in 50 countries. JAMA. 2016;315(8):788-800

2. Anzueto A. Incidence, risk factors and outcome of barotrauma in mechanically ventilated patients. Intens Care Med. 2004;30(4):612-9.

3. Sheu C. Clinical characteristics and outcomes of sepsis-related vs nonsepsis-related ARDS. Chest. 2010;138(3):559-67.

4. Han F. Early initiation of continuous renal replacement therapy improves clinical outcomes in patients with acute respiratory distress syndrome. Am J Med Sci. 2015;349(3):199-205.
5. Timsit JF. Usefulness of a strategy based on bronchoscopy with direct examination of bronchoalveolar lavage fluid in the initial antibiotic therapy of suspected ventilator-associated pneumonia. Intens Care Med. 2001;27(4):640-7.

6. Park JY. Early initiation of continuous renal replacement therapy improves survival of elderly patients with acute kidney injury: a multicenter prospective cohort study. Crit Care. 2016;20:1

7. Stads S. Impaired kidney function at hospital discharge and long-term renal and overall survival in patients who received CRRT. Clin J Am SocNephro. 2013;8(8):1284-91.

8. Woodside KJ. Pneumothorax in patients with acute respiratory distress syndrome: pathophysiology, detection, and treatment. J Intensive Care Med. 2016;18(1):9-20.

9. Boussarsar M. Relationship between ventilatory settings and barotrauma in the acute respiratory distress syndrome. Intens Care Med. 2002;28(4):406-13.

10. Coopersmith CM. Surviving sepsis campaign: Research priorities for sepsis and septic shock. Crit Care Med. 2018;46(8):1334-56.

11. Aubron C. Intravenous immunoglobulin for adjunctive treatment of severe infections in ICUs. CurrOpin Crit Care. 2019;25(5):417-22.

\section{Publisher's Note}

Springer Nature remains neutral with regard to jurisdictional claims in published maps and institutional affiliations.
Ready to submit your research? Choose BMC and benefit from

- fast, convenient online submission

- thorough peer review by experienced researchers in your field

- rapid publication on acceptance

- support for research data, including large and complex data types

- gold Open Access which fosters wider collaboration and increased citations

- maximum visibility for your research: over 100M website views per year

At BMC, research is always in progress.

Learn more biomedcentral.com/submissions 